\title{
How to Discover a New World Without Being in Danger of Wreck
}

\author{
Miguel González-Carbajal Pascual and Ludmila Martínez Leyva \\ Medical Sciences University: Dr. Joaquín Albarrán and Carlos J. Finlay
}

Cuba

\section{Introduction}

The fact that a serpent has been chosen as a component of medicine caduceus should not be surprising because, from his oldest ancestors, man has shown a strong tendency to idolize this species either by his cunning and wisdom or because of the intense vital impulse that is attributed to snakes. The world's oldest ritual, possibly due to an enigmatic cosmogonic influence, was centered on a snake. A professor at the University of Oslo, Sheila Coulson, found evidence of the cult when studying the origin of the San tribe living in a sparsely populated area of northwestern Botswana, Africa. The scientists' team got into a small cave where they found the simulation of a huge snake six feet long carved on a stone. It was a stone with a serpent figure with hundreds of indentations that could have only been made manually by man. Immediately, they decided to excavate beneath the rock searching for the equipment used to make incisions and found many stone tools with which the cuts were made. But most importantly, they found a piece that made up the snake, which should have fallen during the construction, 70 thousand years ago. The world's oldest ritual took place in Africa, (the first finding of this kind took place in Europe 30,000 years before) where a group of homeless and fearful men worshiped a stone boa. It seemed to move by stealth down the torch light due to sinuous anatomy and fissures that had been carved to worship it in some distant connection, knowing that knowledge and strength are attributed to this reptile (Gonzalez, I. 2007). If we stimulate our imagination a little bit, it would be conceivable that one of those men would have been the first to start the men diaspora to all latitudes of Earth from its cradle and source of an African common origin, which could make this fact the predecessor of what we call today Globalization. His name is unknown, unlike the others who followed him through history such as Alexander the Great, Marco Polo and Christopher Columbus as outstanding figures of this complex and fascinating feat in which humanity got in first, with tentative steps and then, with increasing enthusiasm. One of the motives seems to have been the need for communication, prompted by an innate curiosity that lies at the heart of the human species. It has been argued that early hominids got raised to the standing position, encouraged by the desire of discovering what was happening beyond weeds covering the wide savannahs.

If we stick to the Dictionary of the Royal Spanish Language Academy (DRAE in Spanish), we will see that communication has as first meaning: (From lat. communicāre) to share with others what someone has. (DRAE 2001, 22nd edition). However, history has stubbornly taught us that most of the time, when the communication between men takes place, what happens is 
exactly the opposite, that is, oneself is a participant of what someone else has. Sometimes more blatant than others, as soon as the man had a bit more than what was strictly necessary for survival, he became interested in plunder philosophy, an inspiring source of all conflicts. Not even the Great Admiral could elude that fate, and perhaps unintentionally in his overall relationship, addressed to the Catholic Monarchs, the references to the "gold" word count around two hundred times, while he only mentioned the name of the "Almighty" fourteen times. Thus, he revealed accidentally the closest motives that inspired his false devotion feat, which was permeated with a distinctive smell of sulphur, a smell of Devil's claw (Carpentier, A. 1979). When a mugger stops his victim in a dark way and blurts out: Your money or your life! he shows a specific message, very clear indeed.

The grueling route required not only human nature as the driving force, but it also needed science peremptorily so that the steps could go directly to conquer the coveted top of the planetary scale, a prerequisite that authenticates the Globalization concept; and humanity decided to cultivate it and make it progress vehemently. Jean Jacques Rousseau accurately identified man as a social being, and according to him, man was destined at finding a way of association that should defend and protect, against all common forces, the person and goods of each associate, and through which each person together with everyone else, should obey only himself and remain as free as before (Rousseau, 1988). It could be interesting to medicine professionals to find contact points between this idyllic association, that referred the remarkable French philosopher of the Enlightenment, specifically in regard to healthdisease process during humankind inevitable course through Globalization.

If we move a little inside the rough track of medieval thought, so constant in worshipping religious mysticism and liturgical rituals as well as in the proscription and insatiable persecution of witches, wizards, alchemists and freethinkers, we could feel the beneficial influence of the Renaissance breezes, which are impregnated with the freshness that only the relief from a too much heavy burden provides. We could also perceive the reason why is still celebrated the resounding displacement that took place when the man, in his own right, became the center of every interest. It was a historical portentous turning point that embraced society and its cultural values system. Science did not let the chance go, and in the twinkling of an eye, it soon provided the foundation for an unprecedented flowering that would induce an improvement of such great magnitude that indelibly removed contextual frameworks that humanity had in the west.

With these premises, it is not difficult to understand why, taking as a starting point science development since the seventeenth century, the information it produces turned into a normative knowledge pattern, to become almost exclusively the sole and legitimate representative of human wisdom, a phenomenon in which should not be overlooked the seal left by the French Revolution at the end of the next century. Modernity opened a new independent cognitive relationship, which was eventually consolidated. The "reign of reason" became the "reign of experimental science." Today, we can see how a huge portion of humanity assumes scientific thought legitimacy in order to create a predominant trend; over and above which, there are still alive with a particular frequency the magic, the occultism, the necromancy, the astrology, and many other reality approaches to which could be added pseudo-science, the danger of which lies in the fact that, unlike the others, it presents itself as a science.

Knowledge scientific character consists of the fact that, in this case, man deals consciously and in a planned way, with a reality area in order to investigate it and study it deeper, more systematically and accurately than the common man, and achieves to establish the accuracy 
of knowledge thus gained. It is then a specialized activity that becomes a profession in the person of the scientist (Rojas, 1996).

Other specific science qualities that allow its differentiation from everyday thinking and other knowledge forms are: Objectivity, Rationality, Systematicness, Generality, and Fallibility. Science is one of the few man-made systems which explicitly recognize its mistake possibility. The real capacity to overcome resides in this awareness of its limitations. If this work accomplishes to clarify some of the actions brought about by Globalization and the huge technological advances that go along with it, together with the Clinical Method and the doctor-patient relationship; contributes to establish a balanced role to be played by the Evidence Based Medicine powerful movement on the diagnosis and treatment of our patients; collaborates to restore the place that Biostatistics should occupy at these burning issues, and allows us to approach the answer to the question: "Is the association we found in the Globalization process similar to that proposed by Jean Jacques Rousseau?" Then we will consider fully well accomplished our most ambitious aspirations.

\section{Approach to the concept of globalization}

At the beginning of this epigraph, we feel compelled to clarify some points regarding the Globalization concept, a phenomenon difficult to explain, to which many authors have attributed a large number of definitions. We will try that the concept offered here can be comprehensive so that it can help as a reference for the aspects we will analyze. We will also seek to be concise enough so that it can have a proper accreditation.

The Dictionary of the Spanish Royal Academy records "Globalization" as the "tendency of markets and enterprises to increase themselves, reaching a global dimension which transcends national boundaries" (DRAE 2001, 22nd edition). According to this definition, it is a fundamentally economic process.

When people hear about Globalization, they think of a phenomenon born in our time. It seems that the world got globalized just a few years ago. The classics of Marxism, Marx and Engels, even when they did not use the term Globalization in vogue today, were able to see the process as a historical tendency of capitalist development. Globalization is the increasing integration into a sole world capitalist market. It is defended by neo-liberalism embodied in international organizations such as the WTO (World Trade Organization), the IMF (International Monetary Fund) and the WB (World Bank), and it is rejected by antiGlobalization groups (Moran, M. et al. 2008). In 1945, shortly before the end of World War II, the United Nations, still in process of constitution, carried out a financial conference in Bretton Woods, United States, where it is decided to create the International Monetary Fund and World Bank. In that moment, that superpower took control of international financial institutions, where it unflinchingly holds veto power (Castro, F. 2011). Soon after, in 1947, the WTO predecessor is signed, that is the General Agreement on Tariffs and Trade (GATT). In 1971, during Richard Nixon's presidency, United States suspended the dollar conversion into gold. Unlimited U.S. bills were printed with which this nation acquired large properties and wealth in the world, as they had a currency in constant and growing process of devaluation. In 40 years, its value was reduced to $2.5 \%$ from the previous one it had then (Castro, F. 2011). These data explain the rising hegemonic role, played by a nation in the development of Globalization. Understanding extra-economic dimensions of Globalization cover issues that affect all humankind worldwide, among which may be included: immigration, transportation, education, medicine and population health, cultural 
imperialism against multiculturalism, mass media, Internet, climate change, global economic crisis, food crisis and the real danger of a conflagration that could quickly reach international proportions.

\section{Internet: Vehicle or globalization purpose?}

Just because it is a tremendous informative building which has been self-configured, it becomes a leading cultural event, although it has been and is being so essentially chaotic. The prodigious ease with which we can now identify text, sound and pictures, keeping them in our own personal computer and modify them or share them with colleagues; opens up opportunities for scientific culture unsuspected until very recently, especially in the South. And in the specific case of researchers, they are strengthened with the distribution list by email, the access to many journals in all disciplines, the connection to databases and records with information (e.g. demographic and epidemiological), the access to academic institutions, the research centers, and webpages or individual blogs from eminent scientists (Silva, L. 2008). Historically, the most effective way to combat false or misguided information has been to provide genuine and accurate information, but the big challenge is to demarcate each other. It is necessary to insert that, although slow and laborious, the system of conventional scientific journals towards peer review, offers in principle a rigor guarantee that happens to be a good deed not negligible at all, and it is needed mostly while we live in this information flood that usually develops more rapidly than our own ability to rationally assimilate it (Silva, L. 2008). Literacy concept now includes not only words reading and writing, but also computer skills are essential, as well as mathematical, methodological, epidemiological and statistical knowledge. In the information age, the library role assumes a definitive function in "information literacy." The increasing production volume of information requires a growing space for its conservation. It also requires an almost instantaneous dissemination of information as a result of the so-called Globalization process or knowledge internationalization. Factors that have influenced the most the publications movement to new media are: the need for immediate distribution of information, the rising costs of printed editions and paper, contrasting with the accessibility and affordability of modern media. In this way we are, in the health field, with a high percentage of professionals who are only superficially related to the information world. It is considered that to have "information literacy" is " to know when and why you need information, where to find it, and how to evaluate it, use it and communicate it in an ethical way." We live in an increasingly competitive globalized environment, which is in short, a new economic context in which the best source to obtain a sustainable competitive advantage for an organization, region, or society is the continuous innovation and the knowledge that enables such innovation (Casate, R. 2007). Internet is here to stay, and it can be considered as a consequence of Globalization and at the same time, an important driving factor.

\section{Clinical method: Rising and declining. Globalization and technology effects}

\subsection{Background}

Many people tend to repeat that prostitution is the oldest of all trades; if we admit that the massage that is practiced on a swollen and sore area after a surprising bang, is one of the earliest and instinctive attempts to relieve pain and, therefore to exert medicine though 
rudimentary, let me have at least some misgivings about the first in the time of the trades mentioned. What no one will ever put into question is that since it was born, the medical profession was essentially benign, beneficial, and charitable; which aims to cure or relieve disease effects on people. At that time, and even many centuries later, concepts of disease prevention were not important at all, or they were simply not known; and it is remembered how surgeons and dentists, better classified as "tooth-takers", alternated their functions with barbers. The science of first physicians was limited to relationships with patients, and politicians were far from imagining the importance of health care and its promotional program designs, to acquire the development of future societies. Given the powerlessness to carry out many diagnoses and the lack of resources for effective treatment, doctors interacted with patients and their families and thus appeared the so called "bedside doctor" or "family doctor".

The truth is that medical practice only had, at the beginning, the interrogation, physical examination and urine, feces and other patient secretions visual exploration, in order to make their diagnoses. With the gradual introduction of scientific and technical advances in the identification of conditions that patients suffered, there were provided unexpected options to successfully complete a diagnosis process. The microscopy was introduced and urine revealed previously unknown secrets, when only visual examination was available to evaluate its characteristics. Blood, feces and other fluids were thoroughly analyzed with the lens amplification ability. Would it be then, when appeared an irresistible temptation for some medical practitioners to abandon the habit of examining carefully and sometimes even smell the urine and other revolting secretions, to instead indicate a microscopic examination of them, which, besides being more elegant, was a demonstration of scientific progress?

\subsection{The Scientific Method}

Along with all particular methods, there is another one called the scientific or experimental method, common to all sciences, whether applied or theoretical. There is no science without Scientific Method, because it is the research strategy, it is the one that has to do with the entire research cycle and not only to one of its individual parts. It is also independent from the subject or the phenomenon that is selected for analysis or study. The hallmark of science is the Scientific Method. This is a universal, unique, and common method to all sciences; it covers all research, and constitutes its strategy (Moreno cited by Nassif, 2010). There is considerable consensus concerning the fact that the scientific or experimental method was definitely stated by Claude Bernard in 1865, although it was applied some time before. It consists of the following steps or stages: formulation of the problem to be investigated; scientific hypothesis to be proven, design and implementation of experiments that need to be carried out, to verify whether the hypothesis was proven or not, review and re-checking, because no experimental science is checked just once since either chance or favorable bias may have intervened, so we must check and recheck, which is called reproducibility and consistency (Moreno cited by Nassif, 2010)

\subsection{The Clinical Method}

The Clinical Method can be summarized as the application of the Scientific Method by the healthcare doctor to the object of study: the health-disease process in humans. It is simply the Scientific Method applied to the work with patients. When a doctor treats a patient, he also applies the Scientific Method; the difference is that he is not dealing with a laboratory 
experiment with inanimate material or plants and animals, but humans. In this case the patient talks about his discomforts and the doctor gets the symptoms through the interrogation and the signs through physical examination. So, he gets the information needed to immediately establish the presumptive diagnosis hypotheses and checks through the contrast, which, most of the time, is performed by laboratory analysis or other tests called complementary tests. The steps were: formulation, information, hypothesis, contrast and verification. These organized steps or stages consist of the Clinical Method or the diagnosis process, as it is also known. Each time a clinician faces a patient diagnosis, he is carrying out an investigation and makes it through the Scientific Method common to all sciences (Moreno, M. 2001). Nowadays, treatment is included in the Clinical Method due to its close relationship since there is no diagnosis without treatment and it is necessary to have a diagnosis in order to indicate a therapeutic remedy. In addition, the Clinical Method ultimate goal is no other than the application of a treatment to heal or relieve the patient. (Rodríguez, L. 1999).

Scheme No. 1 illustrates the similarity of the Scientific Method and the Clinical Method stages.

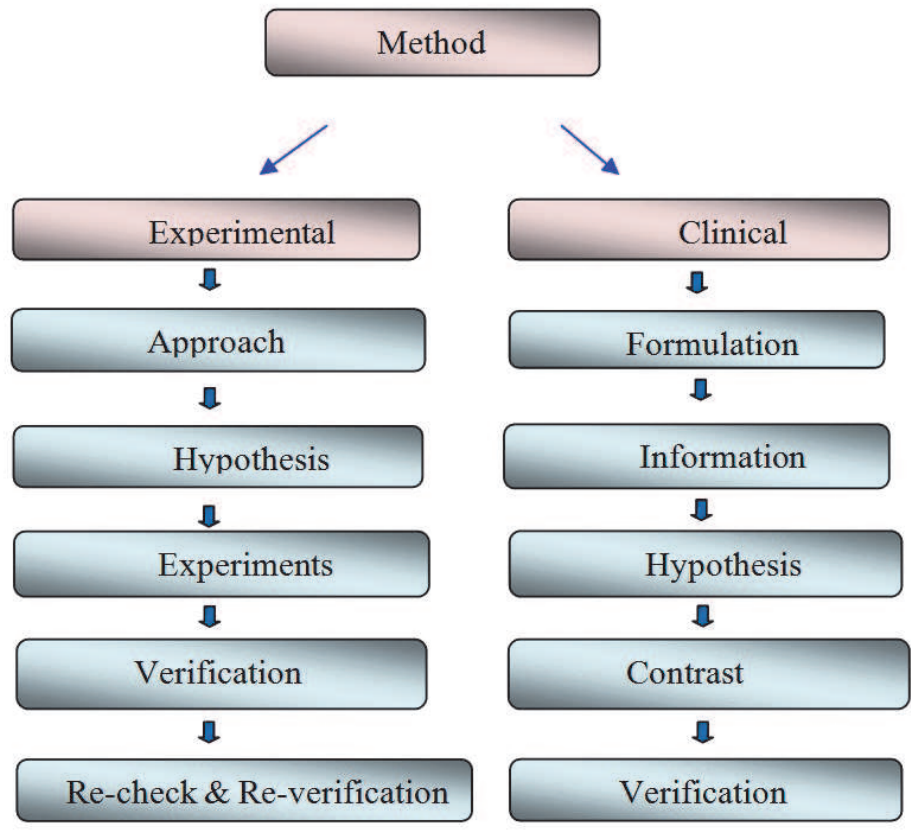

Scheme No.1

When breaking down this scheme can be seen, in regard to clinical methods, the way in which (Ilizástigui \& Rodríguez cited by Nasiff, 2010) each stage of the method depends on the previous one:

Formulation: the problem or problems of the patient. The reason why the patient consults the doctor is because of his health loss.

Information: The search for basic information. It refers specifically to the interrogatory and physical exam, which is equivalent to the clinical history. The physical examination should 
be complete regardless of the organ to which the subjective symptoms may suggest. Previous unsuspected findings in the physical examination have led to accurate diagnosis. Hypothesis: It is, in the Clinical Method, the diagnosis or presumptive diagnoses. Contrast: The presumptive clinical diagnosis is subjected to verification by scheduling additional laboratory tests, imaging, pathology and others. It is also essential to observe the patient's evolution as the results of the tests arrive.

Verification: Finally, there will be an accurate diagnosis that will allow the doctor to indicate some treatment or, what is crucial, the diagnosis hypotheses stated will be denied or new problems will be discovered. The latter will make obligatory to reassess the situation and restart the process.

In the stage of the hypothesis formulation, a procedure that consists of grouping patients' symptoms and signs into syndromes is applied, and thus a syndromic diagnosis can be formulated. Then, the doctor proceeds to examine carefully which diseases, according to the clinical manifestations, could explain the symptoms and signs that the patient presents at that moment. It is basically a rational scientific thought exercise, some call it "medical thinking", in which the clinician proceeds to analyze similarities and differences of diseases that could be responsible for the patient's syndrome or syndromes and are excluded one after the other, the ones that fail to adequately combine with the clinical features of a particular patient. Sometimes the doctor prefers only a clinical diagnosis; it is called like this because in its elaboration there have not been included data provided by complementary examinations. Some other times it is necessary to admit a second or third diagnostic possibility in the patient. All this process is called differential diagnosis and it can be richer and more productive while more clinical knowledge has the one who carries it out. The foundations upon which further examination will be selected to prescribe on each patient and its initial consecutive order depend on the clinical diagnosis, which is equivalent to the hypothesis.

The clinician has the advantage that in addition to symptoms and signs, he can study the sick person; he can also know everything about the patient's life. When delving into the socio-psychological study of the patient, the clinician's work takes on its true dimension of integration. The doctor-patient relationship is the most sensitive and humane aspect of medicine, and the first principle for a correct application of Clinical Method. If the doctor does not establish a positive and cordial human relationship with the patient, he has misspent his chance of succeeding. This type of relationship can not be replaced by the use of apparatus and analysis as modern as they can be, because its content is eminently human. Some doctors do not fully understand that the patients' satisfaction, their views on their caregivers' competence, and their final assessment on the health system efficiency are closely linked to the doctor-patient relationship. Today it is common to speak of good clinical practice. The first rule of good practice is to apply the Clinical Method excellently. There is no science without Scientific Method (Moreno cited by Nassif, 2010).

Urbanity or formal education, as it is nowadays usually called, plays a leading role in the fact that this relationship between patient and doctor, as well as with nurses and other health workers, can flow fruitfully. It is a massive discourtesy that an elderly person, which may be a famous writer, an economics or medicine professor, a skilled worker or a modest street sweeper can be automatically reduced to the status of "my folk", "grandfather" or "grandpa" just because he filled out a hospital admission slip, no matter the good intentions that could have been applied in one case the degrading, and in the other absurd and equally irreverent adjectives, as there is no blood link with the patient. Which right has that that assists in the plethora of his or her youth, to arrogate that inadmissible prerogative stuck to spruce up in a white coat or other health clothing? 
Clinic science takes the general, which is the disease, and combines it with the individual in a close particular dialectical unity that leads to the patient. That is why there are not two patients alike. A doctor attends a patient, not a disease.

The intelligent and rational use of diagnostic means that technology gives us does not create any problem if the hypothesis is put before the contrast, and not the other way around. The use of technology is part of the Clinical Method. Proceeding to the contrast stage without having a clinical hypothesis would indicate a complementary "set" -as it is often calledcarrying out a frantic divination race against scientific procedure. Additional tests exist to be prescribed by stages, gradually, and subjected to a previous formulation of a clinical hypothesis, as each one should be correlated with the initial hypothesis, the patient's evolution and the rest of the results that have been received. Understanding the Clinical Method value in medical practice and to fight for its proper application is the cornerstone of an excellent medical care (Ilizástegui cited by Nassif, 2010).

However, despite all its benefits and its convinced defenders agglutination capacity, many data indicate that the Clinical Method suffers, for decades, a continued deterioration in Cuba and worldwide. This global crisis is manifested by:

- Underestimation of the interrogation value and the physical examination as diagnostic tools.

- Excessive and irrational use of diagnostic technology.

- Deterioration of the doctor-patient relationship.

\subsubsection{Underestimation of the interrogation value and the physical examination as diagnostic tools}

Partly inspired by a "law" that although with degrading consequences is not less attractive, we refer to "comfiness law" or " least effort law ", a growing number of doctors have given up dialoguing with their patients and they perform a superficial physical exam or simply do not do it. Why bothering on getting out of the consulting room or staying bedside of the patient? Since the authors are active practitioners of the profession, we know that, in addition, not all patients present neatly and their illness severe nature -skin lesions, fever, sweats, productive cough, bruises, petechiae, foul breath, etc.- are factors that do not encourage to approach and touch them. To do so, doctors must deeply feel the vocation towards the profession they chose, and they should be convinced that the daily routine lies in the close coexistence with people suffering from diseases that have unpleasant physical manifestations.

Thinking of a diagnostic hypothesis has become a very laborious task, which according to them, should be supplemented by the reference to a barrage of complementary examinations, which with a sudden shot impact with pellets would work the miracle of exposing the patient diagnosis without the awkward situation of wasting time in a lengthy interview and a physical examination, and what represents an even greater burden for those minds: the ominous sacrifice of thinking, an essential condition for developing a diagnostic hypothesis. This volition is more pseudoscientific than misleading; since science recognizes its mistakes. Some doctors, driven by the growing fascination with the technological advances in the field of diagnostic and therapeutic alternatives that are available today, have assumed behavioral methods that, though wrong, have been incorporated to themselves with a pedestrian easiness. Delighted with an inexplicable spell, they forget that science and technology are products of the human brain that can not become their slave.

\subsubsection{Excessive and irrational use of diagnostic technology}

Prof. Miguel Angel Moreno, with his masterful teaching aptitude, gives us this eloquent example of what unfortunately is happening now in the field of clinical diagnosis when 
glossing Karl Marx when he said: "Men have become goods the subject of an almost religious worship; they, creators, have come to surrender to their creatures, the products of their heads have finally seized creators' own heads" (Marx, K. 1973). Similarly, "technology fetishism" has ignited feverishly many physicians' minds, according to Prof. Moreno (Moreno cited by Nassif, 2010), in order to make them sink into the delirious illusion of the fact that technology can provide solutions to the diagnosis uncertainty against the Clinical Method, and without the assistance of semiology, propaedeutic and rational thinking. Almost all imaging scans excepting ultrasound scanning cause human body exposure to radiation in varying amounts, from Roentgen rays to multi-cut helical tomography. There are other investigations, also invasive, in certain indispensable cases such as the endoscopic endoluminal exploration and many others. That is reason enough to justify the Clinical Method use in making decisions that will guide the explorations sequence when examining a patient.

In addition there are economic reasons that can not be underestimated. In many countries there are agreements between physicians and laboratories so that the former receive a bonus for each research they indicate and the patient must pay; of course, the more analysis indications the more profit for the medical professional that recommends it. Such a link has been woven between doctors and drug companies so that the higher the amount of drug prescriptions, the higher the amount of money going to those who prescribe those drugs, which also includes invitations and other perks at the expense of patients' pockets, without being able to obviate the adverse impact on the patient health due to the drugs unjustified prescription. It is possible that sometimes the patient can not afford the economic burden of multiple investigations, many unnecessary, and instead he can be more dissatisfied than grateful to the doctors, who are backwards to the Clinical Method and to the most basic ethics driven by their profitable greed. In other places, where a covering system through insurance is assumed, huge costs come into conflict with the limits that this brings. If a nation health system, as in Cuba, takes the free conducting of any investigations referred by physicians, even the most sophisticated and expensive, the wasting of resources resulting from this procedure is imperative to prioritize rationality recovery when indicating additional tests to patients with the aim of avoiding the risk of making it untenable.

\subsubsection{Deterioration of the doctor-patient relationship}

These mistaken trends have not made their way with impunity, but instead have led doctors to separate themselves from patients and reduce their personal contact with them. It is a bad practice that should be reversed immediately because, if continued, it would entail an irreparable void in medical practice, a discipline eminently social that does not admit being depersonalized as its very essence lies in physical, emotional and affective support that only the doctor is able to provide to a helpless and ill human being -that is beyond co-workers, friends and the closest family members no matter how close they can be. The patient and his family members, regardless of a correct diagnosis and appropriate treatment, require the doctor's presence, the security provided by their professionalism conviction, and the solidarity solely provided by the physician, when doing everything that depends on him in order to restore the patient's health. Medicine is the purest and most human of professions; those who choose it will constantly have opportunities to demonstrate their vocation. It is, in that moment, where the doctor must display his experience and expertise, because the patient's conceptions about his illness vary from one to another as well as the disease presentation; some clinical manifestations are so different that have to be studied and classified as forms of presentation of a particular disease. Each person is a universe in itself, and the minds dark labyrinths usually mask what is unknown to most people and the 
patient reveals only to his doctor. The doctor who forgets that his professional activity center is another human being might be in great troubles. Their success and failure depends largely on the capacity of individualizing each patient. Today it is tangible that, despite the importance of creating a successful doctor-patient relationship, this physical link crumbles rapidly. The removal of this affinity archetype, considered as part of a sterile liturgy or a superfluous ceremonial in the era of modern technology, is a task that does not require too much hard work, as it does with almost all demolition activities. This is part of the current clinical practice in many places, including our country.

\section{Clinical epidemiology, evidence-based medicine and Clinical Method. Incompatible or complementary?}

\subsection{Background}

Beginning with the medical clinic, and according to the author, an inexperienced nephrologist and renal tubule physiologist, David L. Sackett, becomes in 1962, when the missile crisis in Cuba occurred, in a reluctant field epidemiologist at the Public Health Service of the United States. He carried out cardiovascular and epidemiological studies, he learned epidemiology and biostatistics and began to reflect on the area in which new knowledge could be useful to decide to apply them to the clinic rather than population health problems. He did not know initially how to call this discipline until finally decided to borrow a term introduced by John Paul during 1930's decade, he called it clinical epidemiology (Sackett, D. et al. 1989 and Ramis, A. et al. 2005). It basically stated that the application of epidemiological principles and a few more on Biostatistics to beliefs, judgments and intuitions that comprise the art of medicine, could substantially improve the accuracy and efficiency of diagnosis, prognosis, treatment, continuous updating of knowledge and especially the ability to teach others how to do these things. A new School of Medicine at McMaster University gave Sackett, Tugwell and Haynes, the opportunity they craved (Ramis, A. et al. 2005), and that led, perhaps without even imagining it, to build the movement foundations, which later became known as Evidence Based Medicine.

As part of the most remote history of Evidence Based Medicine, there was a movement supported by France in the mid-nineteenth century, which defenders were Pierre C. Louis Alexander, Bichot and Magendie, enthusiastic promoters of the "Medicine d'Observation". They argued that in the clinical practice, doctors should not be solely based on personal experience and their assessments on the position to take towards certain disease, but these should be backed up on research results that will show effects quantitatively. It was clearly observed in the biomedical area, often conservative and attached to the authority, a healthy questioning spirit of those opinions and maneuvers that were based more on tradition than on deliberate reflection and rational synthesis. These fundamentals, proven by A. Louis with the implementation of experiments in which he used his numerical method, revealed the degree of ineffectiveness of some treatments that, at the time, were applied to heal some diseases. Thus, he contributed to the unnecessary therapies removal, and although there were those who described him as a "post-revolutionary skeptical ", his findings had a major impact in France, England and United States of America (Boucourt, L. 2001).

\subsection{Approaching an evidence-based medicine definition}

The term Evidence-Based Medicine emerged in 1992 and was officially mentioned for the first time in an article that can be classified as seminal, and appeared in the Journal 
American Medical Association (JAMA) magazine (Evidence-Based Medicine Working Group, 1992). To practice Evidence-Based Medicine "it is required the integration of best research evidence resulting from our clinical skills and our patients' individual values and preferences". This definition was made by one of the world's most prestigious teams in this field. It appears in a textbook published on the subject and has an Internet website that can be consulted (Strauss, S. et al. 2005). It has been pointed out that the definition is somewhat vague and general because ultimately, everyone might agree with it, but this may not be a defect but a virtue of any definition.

Another way, not essentially different, of approaching the Evidence-Based Medicine concept is the following: "... it is the conscious, explicit and judicious use of the best available evidence when making decisions about a particular patient's care. Evidence-Based Medicine practice means individual clinical expertise integration with the best external clinical evidence available that results from systematic research" (Sackett, D. et al. 1996).

\subsection{Some facts that characterize the present}

Certain facts are unanswerable: (Krabshuis, J. 2007)

- One is the explosive growth of medical information published and the corresponding need, by health professionals, to have this information available and in a way that allows it to be usable.

- The term Evidence-Based Medicine was used in 1996 only 181 times. The number grew to 6452 times in 2004.

- The number of randomized and controlled trials, compared to 1996, has doubled to 15,000 in 2004.

- Traditional information sources such as text books are not as updated as they should be, and some of their recommendations have been discarded as not useful as a guide for decision making at the patient's bedside.

- A rift has been opened between what is known and what is done, that has been identified by doctors and patients.

The Medline database, which is the most important bibliographic database of the United States Medicine National Library, provides an example of the enormous volume of existing medical information. This entity comprises the fields of medicine, dentistry, veterinary science, health care systems and preclinical sciences. It contains citations and author summaries of dozens of thousands biomedical journals published in the United States and other countries. Its files contain more than 20 million references from the mid 60's. Its coverage is worldwide and most records come from English language sources or have English abstracts (National Library of Medicine, n.d.).

Although the Evidence-Based Medicine background dates back to little more than two decades ago, its rapid growth has begun just recently. The $91 \%$ of the work on this subject, processed by Medline in last decade, correspond to the most recent 5 years. It can be admitted that such tests are among the strongest evidence and more vigorous research designs of a research scientific validity in this area of knowledge (Canedo, R. et al. 2003).

The Evidence-Based Medicine is a consequence of the necessity to not only answer but also provide a solution to the problems arising from the situation just described. It is therefore, a natural result of the need to create a new healthcare model capable of integrating solid and clinically useful results of investigations that take place in the health sector with daily clinical practice, in order to achieve high quality care supported on the latest developments in the areas of biomedicine, chemistry, technology, humanities, etc. (Broche, J. et al. 2003). 


\subsection{Classification of scientific evidence and degrees of recommendation}

It was necessary to design a system to classify the level of available evidences on a particular clinical problem according to its origin, because, as these come from various sources, the reliability degree was inevitably different.

In general, the levels proposed can be summarized as (Broche, J. et al. 2003):

Level I. The best evidence that certain treatment is effective in achieving a specific goal derives from a controlled clinical trial. This type of experiment, in its simplest design, compares the drug effect to a placebo, both administered in a way that neither the person supervising the experiment nor the patient knows which one receives the placebo and which one the medicine object of study (double blind). The allocation to each group, either of study or control, is done in a strictly random way. With this process, most of the biases are avoided.

To group a set of studies and analyze the results, it is necessary that they fulfill certain requirements related to homogeneity and other aspects. The result is a meta-analysis that, if done properly, can also be considered as evidence of level 1 (Broche, J. et al. 2003)

Level 2. Basically includes the controlled clinical trials that do not reach enough power to prove, unequivocally, the effectiveness of an intervention; because the results are located around the statistically significant borderline.

Level 3. Includes the controlled clinical trials where randomization is deficient or not enforced, reason why biases can be introduced in assigning patients to one of the study groups. The same occurs with cohort studies. Level 3 evidences should be approached with caution and, wherever possible, carefully analyzed, and should be subjected to consensus groups' approval as far as possible.

Level 4. Includes clinical trials where there is no control group and the results comparison is made with the same individuals before and after treatment. It also covers historical cohort studies. In all these studies may be present multiple biases.

Other evidences. All other types of studies such as case reports or case series, descriptive studies, as well as expert reports, among others, may be useful, but their level of evidence is low. However, sometimes they can be the only information available as it happens, for example, with rare cases or unexpected side effects.

There are other classifications of evidence levels that vary in non-essential aspects of the outlined ones.

In concordance with evidence levels, there have emerged degrees of recommendation as to the behavior to be followed in each clinical problem in an order so that they referred them as A, with maximum evidence, to the D. (Broche, J. et al. 2003)

However, there are strong indications that allow predicting a risk of Evidence Based Medicine wreck that should not be dismissed.

\subsection{Evidence-based medicine. "Denial, use or abuse?}

The Evidence-Based Medicine would be called to revolutionize medicine and to establish a new way to practice it from an integrated conception, where it is consciously unified the individual clinical experience acquired by the physician in his professional performance with the most relevant research outcomes recorded in the scientific and clinical literature (Broche, J. et al. 2003).

There is no room for relativism in medicine. The recommended treatments have real consequences, so we better make sure that they are effective, or at least not harmful. That is the purpose of Evidence-Based Medicine: to base our treatment decisions on the best available science, rather than the prevalence of opinions or experience. 
Some colleagues, however, not only abuse the term but also the extent of its projections. Dr. Bernadine Healy, former director of the Health National Institutes in the United States, in an editorial in the U.S. News and World Report in which she commented on the way EvidenceBased Medicine was going up; she labeled it as "micro-fascism." This way, she said, leads Evidence-Based Medicine directly to a tyranny of medical thought. The term "micro-fascism" is striking, while suggesting a totalitarian management of medical practice by the state so, due to such pronouncements, as expected, controversy aroused (Marchetti, P. et al. 2007).

We have reached a moment in which the abuse of Evidence-Based Medicine involves as much risk as its rejection. The evidence can be manipulated to make marginal benefits seem greater than they are. Even more worrying is that, because of necessity, therapeutic studies tend to focus on treatment for a disease in a homogenous population of middle-aged patients. Our patients are not homogeneous, nor have a single disease and few of them are middle-aged. Many of them are elderly with multiple medical problems which require various interventions. There is no reason to expect that they respond to treatment as ideally as research individuals (Marchetti, P. et al. 2007).

In our hospital, the authors have been witnessing a peculiar situation: a non-negligible proportion of doctors who rely on the Evidence-Based Medicine, sometimes with unusual fury, use the phrase to reinforce their own opinions and biases, which may be in some measure related to the extraordinary rising of the term and its relative novelty. Thus, many Evidence-Based Medicine invocations might not be based at all on the evidence. We are concerned, of course, with the fact that the phrase is being "whisked" to add weight to presumed experts views, or just the view of some specialists and residents. It is true that Evidence-Based Medicine underpins the development of guidelines. However, too often, guidelines are intended to be based on the evidence when they really reflect important biases of committee members, or at least consensus views that may not have unanimity in the conclave itself.

One of the problems with Evidence-Based Medicine is derived from the transferring of data into practice. The evidence is involved in our medical decisions, but we also have to use the evidence in the context of the patient's situation. We would like to believe that the use of best information available warrants per se decision making without biases, but that would be naive.

The way we make decisions involves data, but also involves assessing risks and benefits. Conclusions differ because data alone are not sufficient, and they require an analysis and interpretation that may not be equal, and may even have essential differences. We are in favor of developing the best analysis of the evidence without bias, as far as possible. We need good evidence, but we must always interpret it from an excellent clinical judgment (Marchetti, P. et al. 2007).

The Evidence-Based Medicine can not say the way we should treat patients individually. We have to use Evidence-Based Medicine as a welcoming tool in our process of making individual decisions. To expect more than that of Evidence-Based Medicine would endanger the judicious application of the Clinical Method, and consequently the doctor-patient relationship.

On the other hand, the ones who advocate in favor of Evidence-Based Medicine have the right to point out the dangers that holds to base treatment only on pathophysiological foundations (for example, inotropic agents for heart failure and antiarrhythmic drugs to treat ectopic ventricular beats), representing in this case the theory, not substantiated in practice by appropriate clinical trials. Theory that is not borne out in practice is invalid. But it is never convenient to be exaggerated; de-emphasizing basic science entails certain dangers that hinder 
setting it and the reading support aside. Doing so, would lead us to a formulae approach that would preclude preventing errors in patients who do not comply with certain algorithms.

\subsection{Danger of wrecking and moral breaking down}

"... Certain ugliness has its purpose in the very depths of eternal beauty."

(Hugo, V. 1975)

There is no less important side of the problem because if pseudoscience is an acknowledged science enemy, fraud is equally abhorrent; both have a common platform that is deceit. That is why, while the powerful interests that increasingly dominate the health care might be offended, we must teach people to distinguish the evidence of propaganda and advertising. The Evidence-Based Medicine may suggest that some expensive and profitable drugs, devices and health care programs, are not as good as they seem, according to its reputation. It is expected that this do not cause sympathy for those who obtain profit, power or prestige of the situation.

Consequently, dominant interests face the temptation of manipulating the development of Evidence-Based Medicine, which entails the risk of eventually having a bad reputation, when discredited. The biotech and pharmaceutical companies have come under the mantle of Evidence-Based Medicine, to use it as one of its methods of distributing products, devices, programs and strategies for health and the publication of original clinical studies in world prestigious medical journals that are only the result of research sponsored by them. However, traders know they can not avoid evaluative resources already well settled among professionals, called upon prescribing their products, such as Evidence-Based Medicine principles and statistical evaluations. The management done based on statistical data in the advertising context is still poorly studied, and the scope given for deepening on its management is enormous. However, no alarming signs of manipulation are missing (Silva, L. 2008).

The magazine quality would support the medicine quality, which affects this way writing evidence-based guidelines for their interests. This procedure dynamics and other no less worrisome aspects closely linked to it are reported by David Sackett, universally known personality. He is considered one of the fathers of Evidence-Based Medicine. Oxman did something similar in a publication that turned to be obliged reference for those interested on the subject. The title of the article is quite eloquent: HARLOT, prostitute in English. It provides the following translation when breaking down its initials: how to achieve positive results without lying to overcome the truth (Sackett, D. et al. 2003).

Harlot promises to give drug companies and other clients the results they want. Your medicine may be totally ineffective, but Sackett and Oxman promise to produce positive results in clinical trials as long as the medicine is not much worse than taking a swig of distilled water three times. It is important to note that these results can not be achieved in low quality clinical trials. These authors, experts in the designing and analysis of trials, describe 13 methods for obtaining the desired results.

In other words, we witness a process characterized by a real danger of manipulation in the designing, implementation and analysis of research studies by the dominant interests in an attempt to increase the probability that results are favorable to them. This was an early envisioned peril, even before the authors of this work, by eminent scientists of international prestige to which would be difficult to credibly tick of being permeated of conflicting ideologies with the political and economic balance of their societies, due to their findings on the subject (Sackett, D. et al. 2003). 
In the Globalization era, the Evidence-Based Medicine commercial handling shows the seriousness that entails its vast dissemination. A significant number of authors have felt compelled to denounce this phenomenon that could be characterized by its ubiquity, rather than its eventuality. This has revealed certain procedures employed by pharmaceutical companies to achieve the expected results in their clinical trials (Journal PLOS Medicine, 2005) which include:

- To compare the drug to be promoted with other less effectively known or a placebo. The important thing for patients is not whether the drug is better than nothing, but if it is better than existing treatments.

- The company compares its product with lower doses of the competition medicine.

- One of the tricks lays in the question it seeks to answer (hypothesis) and the trial design.

- Multicenter studies to select the results in places where they have been favorable.

- To carry out studies with subgroups and select those with favorable results.

- To present results that may be more impressive such as the reduction of relative risk rather than absolute risk.

\section{More threats: The tyranny of statistical significance tests, peer review, debates in the "Science" commission and the power drunkenness}

It is widely disseminated the belief that inferential statistics, and particularly statistical significance tests, provide the bulk of objectivity that underpins scientifically the research findings. It is not definitive the objectivity provided by the statistical significance tests, and even by the confidence intervals, used not as a source of reflection, but as substitute statistical significance tests. The use of dichotomous rules takes actually nowhere; although not few people use them thinking that no additional reflection is needed, convinced that statistical significance tests are self-sufficient (Silva, L. 2008).

The Maastricht III Consensus meeting was held in 2005, in which guidelines were drawn to the therapeutic approach of Helicobacter pylori infection (Malfertheiner, P. et al. 2007). According to that meeting, the usefulness of treating dyspeptic patients not studied, based on a $1 \mathrm{~A}$ evidence level and an A recommendation degree, with the "test and treat" strategy, is based on a randomized controlled study carried out by Chiba in Canada with patients of primary health care (Chiba, N . et al. 2002), as shown quoted in the consensus report. Providing such evidence level 1 and recommendation degree $\mathrm{A}$, to the use of the bacterium eradication therapy in patients with any kind of dyspepsia, which have not been studied, based on a single randomized and controlled trial. This would be methodologically reliable according to rules that were previously established; but this approach is contrary to the spirit of scientific thought, because such invitation entails restricting our valuation tools to pragmatism, as if the theory and general knowledge could be superfluous. Accepting therapy, exclusively taking as a starting point the fact that it successfully passed a clinical trial is a methodological error. First, because it opens the doors to the widespread practice of admitting or recommending a procedure, just because "meaning" was gotten. Does the recommendation to indicate appropriate eradication therapy to all patients with not studied dyspepsia have, despite the results of that work, a clinical and epidemiological justification? Is it that, despite that study findings, there are not expected adverse side effects, which include the increasing bacterial resistance and the dissolution of the normal gut flora caused by the use of two antibiotics in a very broad population that cast doubt upon that 
recommendation? Everyone knows that a general recommendation can not be a reasonable option to treat all dyspeptic infected patients with eradication therapy of Helicobacter pylori without even studying them. It simply involves the real danger of delaying the diagnosis of a benign or malignant disease, which can include extra-digestive location. At the same time, it is a strategy that involves treatment with two antibiotics and a proton pump inhibitor of thousands of patients unnecessarily, either because their dyspeptic symptoms respond to an organic cause not related to Helicobacter pylori, as stated above, or because these are functional dyspeptic patients that may not get any benefit from the infection eradication (González-Carbajal, M. and Martinez, L. 2008).

Moreover, that expert panel also recommends to treat with A degree, due to a $1 \mathrm{~A}$ evidence level, all patients with Helicobacter pylori positive functional dyspepsia, also a position without solid foundations (González-Carbajal, M. and Martinez, L. 2008). All the established steps can be followed to perform a productive clinical trial, but the advent of failure is inevitable, as it is deployed on a context of a theoretical and conceptual gap that would serve as a basis. It is essential to distinguish between statistical significance and clinical significance when it comes to analyzing results, and this is the one that should be priority, the statistical significance can be then insignificant (Silva, L. 2008)

Clinical trials are, as mentioned, the most efficient tool for refining knowledge, but it is not difficult to find other examples where statistically significant differences are justly scorned by the scientific community. The famous magazine Annals of Internal Medicine published, at the beginning of the XXI century, a review article (Astin, Harkness and Ernst, 2000). It examines research carried out towards the effectiveness of distance healing methods, among which are included resources as prayer, mental healing, therapeutic touch and spiritual healing. The review included only controlled clinical trials, as a guarantee of a minimum methodological quality. It is surprising that twenty-three experiments that meet these conditions have been found in literature, five of them referred specifically to the use of prayer as a healing method. To observe an illustration, seek the study by Harris et al. (Harris, W. et al. 1999), which attempts to show therapeutic benefits of intercessory prayers on patients from an intensive care unit, who did not know there were others praying for them. Despite having obtained statistical significance, that is, chance is discarded as an explanation according to the "official" rhetoric of classical inference; the fact is that there is no news that therapeutic services have been created based on anonymous prayers in any hospital in the world. This is because we all intimately know that it would be foolish not to qualify the statistical results using our culture, our prior information and common sense (Silva, L. 2008). Unfortunately the eradication of Helicobacter pylori infection as a treatment for not studied dyspepsia, and functional dyspepsia has not been received with the same degree of skepticism, though it stands on an equivalent pedestal.

The pitfalls to make science a more rational activity may actually be accented as a result of thoughtless acceptance of the verdict that provides statistical significance tests. The following confirmation is valid. The issue of "intercession by prayer" has attracted the attention of the Cochrane Collaboration, which in its recent review on the topic (Roberts, A. et al. 2003), surprisingly finds that "the evidence presented so far is interesting enough as to warrant further study." It is amazing that this organization, the greatest exponent and promoter of the so-called Evidence-Based Medicine, which has advocated for over twenty years the need to make decisions concerning health care grounded in sound scientific evidence, call for more research on a therapeutic procedure which only support comes from the application of a highly disputed resource: Statistical Significance Tests. The network of 
vertebrate misunderstandings can lead up to that point regarding this technique, which is able to provide absolutely undeserved guarantees. (Silva, L. 2008). Once again, the human intelligence product, its tool, daringly tries to subdue the rational thought that was its forge. The peer review itself, considered an important extension of the scientific process depends largely on how to deal with interest conflicts. Financial relations -such as employment, consultancies, stock ownership, honoraria, and expert reports- are interest conflicts more easily detected and most likely to undermine the journal, authors and the science selfcredibility. However, conflicts can occur for other reasons such as personal and academic competition. Participants in the peer review and the publication process should declare all relationships that could be considered as a potential interest conflict. Editors might well avoid selecting external reviewers with interest conflicts, for example, those working in the same department or institution as any of the authors. The referees, if decent, should disclose to editors any interest conflict that could affect their views on the manuscript, and they should refrain from evaluating manuscripts when these biased factors are present. Therefore, reviewers will be asked to explicitly set out whether or not these conflicts exist. To illustrate it, consider the following example. The author of the manuscript proposed for publication has just broken its link with an institution due to obvious conflict with the director, and it is given to the latter -who shamelessly declares no problem- the arbitration on the manuscript with full powers to veto it. Of course, the former employee, now turned into an ungrateful person and perhaps considered as an opponent by the sordid manager, shall suffer the punishment of seeing his article rejected with the most childish excuses-that automatically transmutes the very well inspired peer review evaluation system in a cheap parody, the basis of which is a dirty vendetta, that suits more to film scripts as The Godfather saga, than the ethical behavior of real scientists.

There will be people enough to discuss these issues and, as it is usual on scientific commissions' debates, encouraged by arrogance, they reveal that under the science thin film covering there are no differences with respect to an excited fan, and it overflows in primitive impulses, behaving like a football fan. This procedure is not completely useless if considered that, sometimes, who chairs the "scientific" committee is affected by an incurable disease that is characterized by suffering from a rabbit heart and newborn mare's legs.

Power provides certain non-negligible opportunities for mediocre people; one can be rough, brutal, and moody under its shade. These men abused their performance to, blinded by vanity, enjoy punishing viciously in the professional and academic order, beyond their guilt, personal enemies -or branded by them as such- that can take dissimilar identities, for example, the incautious son-in-law who, indifferently abandoned the gentleman's daughter, or who despite providing unrestricted support aroused professional jealousy -every privilege, as mean as it can be, bid for solitary fulguration without other light that could play down its carats, or another one with "opponent" requirements. Containment mechanisms of these behavioral patterns, which are legally established, may fail -to what they bet, blinded by the thirst of false compensation- either working or not; the cost in prestige of our presumptuous Guru apprentice will be inestimable. The power shown off, finally make them kneel to themselves, and produces some kind of grievous metamorphosis from which they can never be free; screws from Pandora's box got loosen and appear strange monsters. The village and tribal feeling that works as cradle to these dejected vanities must definitely disappear from science scenery; the apparently cryptic origin of these actions lies on the cavemen clan, strongly nailed on a science representative. Purity deserves respect, and must be praised. 


\section{An attempt to synthesize and some reflections}

The principle expressing that only a minority of decisions taken for a patient's diagnosis and treatment are substantiated through randomized clinical trials, involves a scientific rigor that aims to make the results of biomedical research available to the medical practice, in order to contribute with more science to medicine, based on literature review relevant strategies, meta-analysis, disease treatment guidelines, and most importantly, to educate doctors since they are studying medicine on statistical techniques that allow them to find their way and find the right individual diagnosis, and to apply appropriate treatment, which is an excellent solution to the problem of knowledge (Vidal, M. et al. 2005).

Classics manifest oppositely, defenders of the Clinical Method that assesses the patient as an individual entity, in which medical personal experience in decision making plays an important role due to the diagnosis uncertainty and appropriate treatment. This disjunction between the Clinical Method and the evidence, between experience and evidence is what has provoked many disagreements that make controversial the issue (Vidal, M. et al. 2005).

Does the Evidence-Based Medicine imply that deviation? We do not think so. It depends on the doctors themselves, their ethical principles and proper use of Clinical Method that in such a way is at odds with the challenge that represents the responsible and sensible adoption of Evidence-Based Medicine, which, as the scientific progress in general has come to stay and its irreversibility is unknown. Rather, we dare to ensure that the Clinical Method, the doctor-patient relationship, clinical epidemiology, Evidence-Based Medicine and more rigorous application of the research methodological principles are all important branches of one same tree, which complement each other.

Nowadays, the resolvent scope of medical science remains indeed very limited. Professional success in terms of sound judgment and acceptance does not rise linearly with theoretical and practical mastery of the performer. Psychological and emotional aspects involved in the doctor-patient relationship can hardly be prescribed and proper handling of this connection decisively influences the physician performance acceptance by the patient. The emotional and intuitive implication is inherent to professional action in this area. Individual, psychological, behavioral, cultural and social genetic development of each patient requires a specific and unique approach (Vidal, M. et al. 2005)

The following statements summarize the arguments just outlined, and to a greater or lesser extent, might be assumed that they are shared by major authors that have been devoted to the topic (Sackett, D. et al. 1996) (Vidal, M. et al. 2005) (Gordon, G. et al. 2004):

- A good doctor uses individual clinical expertise with the best available external evidence.

- Neither clinical experience nor available external evidence, separately, is sufficient.

- Without clinical experience, medical practice takes the risk of being tyrannized by external evidence.

- Excellent external evidence may be inapplicable to a particular patient.

- Without updated external evidence, clinical practice is in danger of being outdated at the expense of patients.

\section{Conclusions}

Globalization is irreversible, and its influences on medical science and the medicine practice are radical and deep, which does not imply that they should be taken at any price and with fundamentalist rage; that would only contribute to foster another threat more: to assume as 
true an innocent, sweetened, apathetic vision of the problem, impregnated with an unforgivable Panglossian, deluded, defenseless, and uncritical optimism. The Clinical Method, clinical epidemiology and its most refined contextual expression in the present, and the Evidence-Based Medicine are leafy branches that are part and parcel of what it is and should be a same tree: the Medical Sciences.

The way of science is fraught with danger. We have mentioned some such as pseudoscience, alienated use of statistical significance tests, the tendentious use peer review procedure, frivolity, comfiness, the personal behavior not consistent with scientific ethics during the debate on a scientific problem that pervades certain mentalities. They are vices which constitute a clear danger of sinking.

Some believe that the great difference in the greatness of a medical researcher currently resides, not in the depth of his pathophysiological knowledge, much less in the extent of his clinical skills. Today, as declared emphatically, the final characterization is given by the knowledge on research methodology and biostatistics that this professional has been able to hoard up. The mastery of the clinic and the study of diseases is, to these thinkers, an arid task if wanted but not hard, intricate, dignified by mathematics complexity and the axioms and theorems that provide sustenance to biostatistics science, which by the way, assisted by computer has been remarkably simplified in its applications when the machine performs arithmetic processes that were previously occupied by the biostatistician. Unquestionably, to successfully develop in the world of contemporary medical research is required to get in as deeply as possible in the study of research methodology and biostatistics; it is an important difference between some doctors and others, but not the principal. The truth is that there are other contrasts that leave a lasting impression among medical professionals, such as the one that stands between impersonal medical cares, dehumanized, rejecting the Clinical Method in the practice and the rational medicine that bases on it, and equally provides psychosocial care that patients and their families demand and highly need. We could name others, which does not constitute the most fearsome of the risks and are summarized below.

We can not lose sight of the fact that scientists are so exposed to material temptations as anyone. Subsidies, awards, jobs, invitations, fame, honors, rights coming from patents and monetary compensation are disputed. And these motivations may be equal to or greater than those of finding and disseminating new knowledge (Hauptman, R. 1999).

It is chilling to reflect upon the resistance capacity of a scientist under the perfidious influence of a social environment in which there are many privileges and perks for those who learn to submit their wills to spurious interests. The debasing seed will find welcoming refuge in the grooves given by the companies where the profit motive reigns omnipresent on all mechanisms that determine human activity; but there is no immune social system since depravity seductive figure goes beyond the purely financial dimension to adopt, as sinister Fantomas, the faces of other sinecures that cover the broad spectrum going from a managerial assistance, ministerial position, editorship on scientific journals, and educational category to any other comfortable prerogative, which at times is hard working, but the exquisite charm that power confers is enjoyable. In addition, it is almost always accompanied by the exemption of direct care activities, which astonishingly represents, for certain characters, a burdensome tiredness. When bribes are not succulent and there are not big favors like late-model cars or juicy cash bonuses, takes space voraciously the sailor greed to see more and more filled with cheap goods the duffel bag.

The truth is that the wreck of science, society as a whole, and of humanity itself, on which it has operated -while also starring it- the immeasurable process of Globalization, depends on 
a substantial disjunctive which is not other than the one that throbs and expands between mercenaries without morals or principles, and honest men who defend decency as part of their essential values, even though many others discard them. That is the cardinal difference between some doctors and scientists and others, among some men and others. At the same time it is the main danger on which, later or earlier, a doctor or scientist should make a decision, and when that time comes, he will be alone with his conscience.

The paths that lie ahead are impenetrable but can not be separated from this ethical duality. There is a way -perhaps the only one- to face this pressing problem of science and man. The task is peculiarly difficult if we take into account the concept of Globalization issued at the beginning of this article- there is no easy worthy task. It consists of challenging the powerful dominant forces at the international and national level to disseminate the values we believe at the cost of any sacrifice, to cultivate modesty, selflessness, solidarity, altruism, to report the fraud every time their hairy ears are seen, with the aim of achieving an equality and freedom order, and to be treated and treat others with the generosity they deserve as human beings, as we have the right to be properly treated, regardless of geographic area to which someone can belong to or the financial position they may have. This challenge requires never lying or violating ethical principles, and to act with courage, intelligence and realism, which will enable us to make tangible the longing to transform everything that needs to be transformed in the Globalization formidable process. Alonso Quijano is awake and the chevalier Bayard has a lot to do with us. Some will smile sardonically at the exposition of these views, without realizing that this is not a trivial utopia or a childish nonsense of improvised acquisition, let alone unleashing a furtive iconoclast vocation; on the contrary, it is the essence of the human condition from its most remote origins and the significance of its consequences. Remember Ariel (Shakespeare, W. 1948), to whom William Shakespeare, perhaps the most universal writer in the English language, idealized. Ariel is the greatness and the source of inspiration. He represents the tenacious struggle in pursuit of perfectibility. He gets turning human clay, sometimes miserable, into virtue; the beast that man carries inside into mercy. He is the eruption of the spirit forces. He embodies the man noblest aspirations synthesized in honest disinterest; he is a call to courage, bravery and the renouncing of temptation. He is the idol in the human enterprise. His irresistible force encourages the upward march of life. Thousand times mocked by opportunism and the lack of scruples of Caliban, condemned by perishable winners, bites the dust of defeat in many battles, but does not surrender. He knows no discouragement and he always runs glowing to justice demands. His enemies respect him and his example goes through and still catches his deniers. Many Ariels must rise from humanity, conscious leaders, champions of decorum, and apostles of dignity so that humanity cherished longest and most spread dream become a reality: Globalization of brotherhood. Globalization thus, will resemble the delicious partnership envisioned by Rousseau and we could conquer a new world better than this, despite all the dangers and risks. This way, next port will be not only a miserable place for arrivals, but a fugacious transit scale to the future. The complexity of the matter is summarized in a concise dilemma: wrecking or seizure of the world's second dawn.

\section{References}

Carpentier, A. (1979) El Arpa y la sombra. Capítulo II Pág. 99. Editorial Letras Cubanas. Ciudad de La Habana. Cuba.

González-Carbajal, M. y Martínez, L. (2008) Maastricht III y dispepsia. razones para una discrepancia. Revista Cubana de Medicina. Vol.47, No. 4. 
Harris, W.S. et al. (1999). A randomized, controlled trial of effects of remote, intercessory prayer on outcomes in patients admitted to the coronary care unit. Archives of Internal Medicine 159: 2273-2278

Hauptman, R. (1999). Research misconduct: why are definitions so elusive? Science and Engineering Ethics 5: 443-444 in Silva, L. (2008) La Investigación biomédica y sus laberintos. En defensa de la racionalidad para la ciencia del siglo XXI. Ediciones Díaz de Santos. Impreso en España. Cap IV.

González , I. (2007) Un Rito Giró la Manecilla de Europa a África. Orbe. Semanario Internacional Editado por Prensa Latina. Sección de Ciencia y Técnica. 30 de Diciembre al 5 de Enero de 2007. pp. 13

Hugo, V. (1975) Los Miserables. Tomo 2. Cossete Cap II. Dos retratos completados. Editorial de Arte y Literatura. La Habana, 1975. Pág. 140.

Microsoft Encarta® 2009. Microsoft Corporation 2008. Reservados todos los derechos.

Nassif, A. et al. (2010) Método Clínico, In: Práctica clínica, Editorial de Ciencias Médicas. pp 1628 ISBN 978-959-212-568-1. La Habana. Cuba

Real Academia Española: Diccionario de la Lengua Española. (2001) 22a edición. Madrid. En Microsoft Encarta® 2009. Microsoft Corporation 2008. Reservados todos los derechos

Rodríguez, H. et al. (n.d) El Método clínico. Mesa Redonda. Video. Departamento de Divulgación y Docencia Ministerio de Salud Pública de Cuba.

Rojas, R. (1996) Guía para realizar investigaciones sociales. (Edición: 18a. Ed.)Plaza Valdés. México DF MX.

Rousseau, J. (1988) El contrato social o Principios de derecho político. Estudio preliminar y traducción de María José Villaverde. Madrid: Editorial Tecnos.

Shakespeare, W. (1948) Four Great Comedies. The tempest. Pocket Book, Inc. Edition. New York. pp 272-338.

Silva, C. (2008) La Investigación biomédica y sus laberintos. En defensa de la racionalidad para la ciencia del siglo XXI. Ediciones Díaz de Santos. Impreso en España.

\subsection{World Wide Web sites and other electronic sources}

Boucourt, L. (2001)Su excelencia: la medicina basada en evidencias. In: ACIMED [publicación periódica en línea]. 25.06.2005 Available from : http://bvs.sld.cu/revistas/aci/vol11_5_03/aci07503.htm. Acceso: 15 Mayo del 2008

Broche, J. et al. (2003) Medicina basada en la evidencia: un reto para el médico contemporáneo. In: ACIMED. No 6. Vol 11. nov-dic. 15.10.2008. Available from : http://bvs.sld.cu/revistas/aci/vol11_6_03/aci02603.htm\#cargo.

Cañedo, R. et al. (2003) De la medicina popular a la medicina basada en evidencia: estado de la investigación científica en el campo de la medicina tradicional Contribuciones Cortas In: ACIMED, 11(5). 18.10.2008. Available from:

http://bvs.sld.cu/revistas/aci/vol11_5_03/aci07503.htm\#autor. Acceso: 18 de Octubre del 2008.

Casate, R. (2007) El cuadro de mando integral como herramienta para la gestión. In: La dirección estratégica en la sociedad del conocimiento. Parte I. ACIMED; 15(6). 13.01.2010. Available from: http://bvs.sld.cu/revistas/aci/vol15_6_07/aci02607.htm)

Chiba, N. et al. (2002) Treating Helicobacter pylori infection in primary care patients with uninvestigated dyspepsia: the Canadian adult dyspepsia empiric treatmentHelicobacter pylori positive (CADET-Hp) randomised controlled trial. In BMJ. 03.02.2011. Available from: http:// bmj.com.

Sackett, D. et al. (1996)Evidence Based Medicine: what it is and what it isn't. In: BMJ; 312:71-72 -13 January. 06 .02. 2011 Available from: 
http://bmj.com/cgi/content/full/312/7023/71.

Evidence-Based Medicine Working Group. (1992)Evidence-Based Medicine: a new approach to teaching the practice of medicine. In: JAMA; 268: 2420-5.

Gordon, G. et al. (2004) Evidence based medicine has come a long way. In: BMJ ;329:990991 .30.10.2010. Available from: doi:10.1136/bmj.329.7473.990.

Krabshuis, J. (2007)Evidence-Based Medicine - Why Did it Take the World by Storm. World Gastroenterology Organisation (WGO). In: Setting Global Standards in Education and Training.htm. 29.09.2008. Available from http://www.omge.org/?publication .

Malfertheiner, P. et al. (2007) Current concepts in the management of Helicobacter pylori infection. In:The Maastricht III Consensus Report. Published online 17 Jan. 25.01.2010. Available from: http:/ / gut.bmj.com/cgi/content/abstract/gut.2006.101634v2..

Marchetti, P.et al. (2007) "Evidence-Based Medicine" disminish the physician's role? In: Medscape Students; 9(1). 15.10.2008. Available from: http:/ / www.medscape.com/viewarticle/549329?src=mp.

Medical Journals are an Extensión of the Marketing Arm of Pharmaceutical Companies . (2005) In: Revista PLOSMedicine Vol 2, No.5, May. 20.10.2008. Available from: http://medicine.plosjournals.org/per/serv/? request=get.document\&doi=10.1371/journal.pmed.0020138.

Morán, M. and Flórez, D. (2008) La globalización en América Latina: Economía. 02.02.2011. Available from: http:/ / www.slideshare.net/guest284235/la-globalizacin-en-america-latina.

National Library of Medicine. PubMed Overview. 06.02.201. Available from: http://www.ncbi.nlm.nih.gov/entrez/query/static/overview.html

Ramis, A.et al. (2005) Origen e intencionalidad de la epidemiología clínica. In :Rev Cubana Salud Pública, vol.31, no.3, p.0-0. ISSN 0864-3466.

Sackett, D. et al (2003) AD. HARLOT plc: An amalgamation of the World's two oldest professions. In: BMJ 327: 1442-14445.

Strauss, S. et al. (2005) Evidence-based medicine: how to practice and teach EBM, 3rd ed. Edinburgh: Elsevier/Churchill Livingstone,. ISBN 0443074445. 17.10.2008. Available from : http://www.cebm.utoronto.ca/.

Vidal, M. et al. (2005) Medicina basada en la evidencia. Reflexiones sobre el tema. Revista Cubana Educ Med Superv.19 n.1 Ciudad de La Habana ene.-mar. 15.10.2008. Available from: http://scielo.sld.cu/scielo.php?pid=s0864_21412005000100010\&script=sci_arttext\#cargo.

Vidal, M. et al. (2005) La enseñanza clínica. Reflexiones sobre el tema. In: Revista Educación Superior (En línea) 01.01.2011. Available from: http://bvs.sld.cu/revistas/ems/vol 19_2_05/ems 10205.htm. 


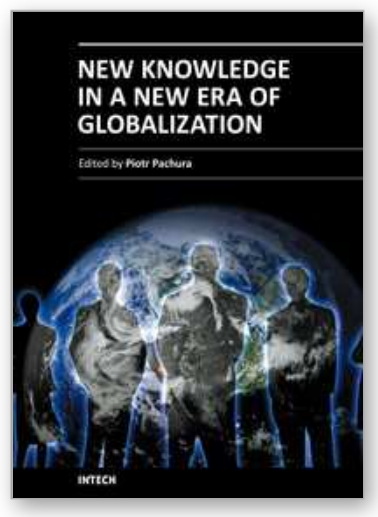

\author{
New Knowledge in a New Era of Globalization \\ Edited by Prof. Piotr Pachura
}

ISBN 978-953-307-501-3

Hard cover, 354 pages

Publisher InTech

Published online 01, August, 2011

Published in print edition August, 2011

To better understand the contemporary world, the world of innovation and technology, science should try to synthesize and assimilate social science in the development of our civilization. Does the new era require new knowledge? Does the age of globalization demand new education, new human attitudes? This books tries to clarify these questions. The book New Knowledge in a New Era of Globalization consists of 16 chapters divided into three sections: Globalization and Education; Globalization and Human Being; Globalization and Space. The Authors of respective chapters represent a great diversity of disciplines and methodological approaches as well as a variety of academic culture. This book is a valuable contribution and it will certainly be appreciated by a global community of scholars.

\title{
How to reference
}

In order to correctly reference this scholarly work, feel free to copy and paste the following:

Miguel González-Carbajal Pascual and Ludmila Martinez Leyva (2011). How to Discover a New World Without Being in Danger of Wreck, New Knowledge in a New Era of Globalization, Prof. Piotr Pachura (Ed.), ISBN: 978953-307-501-3, InTech, Available from: http://www.intechopen.com/books/new-knowledge-in-a-new-era-ofglobalization/how-to-discover-a-new-world-without-being-in-danger-of-wreck

\section{INTECH}

open science | open minds

\author{
InTech Europe \\ University Campus STeP Ri \\ Slavka Krautzeka 83/A \\ 51000 Rijeka, Croatia \\ Phone: +385 (51) 770447 \\ Fax: +385 (51) 686166 \\ www.intechopen.com
}

\author{
InTech China \\ Unit 405, Office Block, Hotel Equatorial Shanghai \\ No.65, Yan An Road (West), Shanghai, 200040, China \\ 中国上海市延安西路65号上海国际贵都大饭店办公楼405单元 \\ Phone: +86-21-62489820 \\ Fax: +86-21-62489821
}


(C) 2011 The Author(s). Licensee IntechOpen. This chapter is distributed under the terms of the Creative Commons Attribution-NonCommercialShareAlike-3.0 License, which permits use, distribution and reproduction for non-commercial purposes, provided the original is properly cited and derivative works building on this content are distributed under the same license. 